\title{
Fluid resuscitation in the management of early septic shock (FINESS): a randomized controlled feasibility trial
}

\section{[La réanimation liquidienne dans la prise en charge du début du choc septique}

\section{(FINESS) : une étude randomisée contrôlée de faisabilité]}

Lauralyn A. McIntyre MD, ${ }^{\star}$ Dean Fergusson rhD, $†$ Deborah J. Cook MD, $\ddagger$ Nigel Rankin MD, $\$$ Vinay Dhingra $\mathrm{MD}, \|$ John Granton $\mathrm{MD},{ }^{* *}$ Sheldon Magder $\mathrm{MD}, \dagger \dagger$ Ian Stiell $\mathrm{MD}, \ddagger \ddagger$ Monica Taljaard PhD,$\dagger$ Paul C. Hebert MD, ${ }^{\star}$ for the Canadian Critical Care Trials Group

Background: It is unknown whether fluid resuscitation with colloid or crystalloid in patients with severe sepsis or septic shock is associated with an improvement in clinical outcome. This randomized controlled trial determined the feasibility of conducting a large trial testing resuscitation with pentastarch vs normal saline in early septic shock, powered for a difference in mortality.

Methods: At three Canadian and one New Zealand academic centre, $\mathbf{4 0}$ patients with early septic shock defined by at least two systemic inflammatory response syndrome criteria, infectious source, and persistent hypotension after $\geq 1 \mathrm{~L}$ of crystalloid fluid were recruited. Feasibility measures were patient recruitment, blinding of the study fluids, and acceptability of the goal directed algorithms. Boluses of blinded normal saline or pentastarch $\left(500 \mathrm{~mL}\right.$ - maximum $3 \mathrm{~L}$ or $\left.28 \mathrm{~mL} \cdot \mathrm{kg}^{-1}\right)$ were administered within goal directed care for the first $12 \mathrm{hr}$.

Results: Of 161 patients screened, 121 were excluded and 40 patients were enrolled, for a recruitment rate of 0.75 patients/ site/month. Only $57 \%$ of physicians and $54 \%$ of nurses correctly guessed the study fluid $(P=0.46$ and $P=0.67$, respectively). The goal directed algorithms were acceptable to $97 \%$ of physicians.

Conclusion: The ability to recruit patients in this pilot randomized controlled trial was below expectations. Blinding of study fluids was adequate, and resuscitation algorithms were accept- able to most physicians. Methods to improve recruitment are required to enhance the feasibility of conducting a multicentre fluid resuscitation trial in early septic shock.

CAN J ANESTH 2008/55: $12 /$ pp 819-826

Contexte: Nous ne savons pas si la réanimation liquidienne avec des colloïdes ou des cristalloïdes chez les patients présentant un sepsis grave ou un choc septique est associée à un devenir clinique meilleur. Cette étude randomisée contrôlée a déterminé la faisabilité d'une étude d'envergure testant la réanimation avec le pentastarch par rapport au sérum physiologique en début de choc septique, avec pour objectif primaire de détecter une différence dans les taux de mortalité.

Méthode: Quarante patients en début de choc septique, défini comme au moins deux critères du syndrome de réaction inflammatoire, une source d'infection et une hypotension persistante après $\geq I$ L de cristalloïde ont été recrutés dans trois centres universitaires canadiens et un centre néo-zélandais. Les mesures de faisabilité étaient : le recrutement des patients, le masquage des liquides à l'étude, et l'acceptabilité des algorithmes dirigés vers des objectifs. Des bolus de normal salin ou de pentastarch $(500 \mathrm{~mL}$

From the University of Ottawa Centre for Transfusion and Critical Care Research, Clinical Epidemiology Unit of the Ottawa Hospital, ${ }^{*}$ Ottawa, Ontario, Canada; Ottawa Health Research Institute; the Ottawa Health Research Institute, Clinical Epidemiology Program of the Ottawa Hospital, † Ottawa, Ontario, Canada; the Clarity Research Group, Department of Medicine and Clinical Epidemiology \& Biostatistics, McMaster University Health Sciences Centre, $\ddagger$ Hamilton, Ontario, Canada; the Middlemore Hospital, $\$$ Auckland, New Zealand; the Vancouver General Hospital, || Vancouver, British Columbia, Canada; the University Health Network, University of Toronto, ** Toronto, Ontario, Canada; the Royal Victoria Hospital, †† Montreal, Quebec, Canada; the Emergency Medicine, Ottawa Health Research Institute, $\ddagger \ddagger$ University of Ottawa, Ottawa, Ontario, Canada.

Address correspondence to: Dr. Lauralyn McIntyre, Box 201, 501 Smyth Road, Ottawa, Ontario K1H 8L6, Canada.

Phone: 613-737-8899 x73231; Fax: 613-739-6266; E-mail: Imcintyre@ottawahospital.on.ca

Sources of funding and conflicts of interest: Dr. McIntyre has received unrestricted funds from Bristol Myers Squibb and Edwards Life Sciences to conduct this trial. She has also received unrestricted funds from Abbott Laboratories.

Accepted for publication August 11, 2008.

Revision accepted September 24, 2008. 
- maximum 3 L ou $28 \mathrm{~mL} \cdot \mathrm{kg}^{-1}$ ) ont été administrés en aveugle dans le cadre de soins guidés dirigés vers des objectifs durant les 12 premières heures.

Résultats : Sur 161 patients dépistés, 121 ont été exclus et 40 patients recrutés dans le cadre de l'étude, avec un taux de recrutement de 0,75 patient/site/mois. Seulement $57 \%$ des médecins et $54 \%$ des infirmières ont réussi à deviner correctement le type de liquide à l'étude ( $P=0,46$ et $P=0,67$, respectivement). Les algorithmes ont été jugés acceptables par $97 \%$ des médecins.

Conclusion : La capacité à recruter des patients pour cette étude pilote randomisée contrôlée était mains importante qu'attendue. Le masquage des liquides était satisfaisant, et les algorithmes de réanimation ont été jugés acceptables par la majorité des médecins. Des méthodes dans le but d'améliorer le recrutement sont nécessaire pour accroître la faisabilité d'une étude multicentrique sur la réanimation liquidienne en début de choc septique.

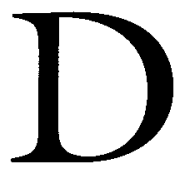
espite more than 20 years of intense therapeutic investigation, mortality from septic shock has remained at approximately $40 \%-50 \% .^{1}$ Fluid resuscitation is an integral component in the management of severe sepsis and septic shock, but until recently there has been a lack of definitive evidence to guide the clinician as to the optimal choice of resuscitation fluid. ${ }^{2,3} \mathrm{New}$ clinical evidence in severe sepsis and septic shock is emerging and suggests that in comparison to normal saline, 5\% albumin may reduce mortality; in contrast, pentastarch may increase mortality as well as the requirement for renal replacement therapy as compared to a lactatebuffered crystalloid fluid. 4,5

Physicians who favour the use of colloids argue that hypo-oncotic crystalloids leak from the plasma to excessively expand the interstitial fluid volume. ${ }^{6}$ In contrast to crystalloid solutions, colloid solutions are macromolecules that under normal physiologic conditions do not pass through the endothelial layer into the interstitial space. ${ }^{7}$ Thus, colloids have the potential advantage of requiring much less volume to expand the intravascular space in comparison to crystalloids. In abnormal physiological states such as severe sepsis and septic shock where endothelial injury is present, this theory may not hold true. Thus, advocates of crystalloid solutions suggest that leakage of colloid into the interstitial space may also contribute to edema formation ${ }^{6}$ particularly in the setting of endothelial injury. ${ }^{8}$ Colloids trapped in the interstitial space create an osmotic gradient and pull additional water into the interstitial space.

The two types of colloid resuscitation fluids available for use in Canada are albumin (5\% and 25\%) and the hydroxyethyl starch (HES) fluids; the main resuscitation crystalloid fluids are normal saline and Ringer's lactate. In a survey of Canadian intensive care unit (ICU) physician early septic shock resuscitation practices, pentastarch and normal saline were the two most frequently cited colloid and crystalloid resuscitation fluids respectively. ${ }^{9}$

Since pentastarch and normal saline were the two dominant colloid and crystalloid fluids used for resuscitation in early septic shock in Canada, we were interested in determining which of these fluids, administered within the context of early goal directed therapy, was the best resuscitation strategy in this setting.

During the design phase of this early septic shock fluid resuscitation trial, our co-investigative team and the Canadian Critical Care Trials Group identified several potential challenges. These included the tight timelines for patient enrolment, use of deferred consent, and the complexity of the interventions. Hence, the objective of this randomized controlled trial was to understand the feasibility of conducting a future large trial testing resuscitation with pentastarch os normal saline in early septic shock, powered for a difference in mortality.

\section{Methods}

\section{Protocol design}

A pilot randomized multicentre trial named FINESS (Fluid Resuscitation in the Early Management of Septic Shock) compared pentastarch ws normal saline for fluid resuscitation within the context of goal directed therapy for patients with early septic shock. Approval to conduct this study was obtained from the ethics boards at each participating site. Approval for deferred consent from the respective research ethics boards was granted for all participating centres.

\section{Study participants}

Patients with early septic shock were recruited from the emergency department (ED), ICU, hospital wards, step down units, and postoperative recovery units. Patients were included into the study if they met all of the following three criteria:

1) hypotension defined by any of the following: (i) systolic blood pressure $<90 \mathrm{mmHg}$ or $<40 \mathrm{mmHg}$ below baseline; or (ii) mean arterial pressure $<65$ $\mathrm{mmHg}$; or (iii) need for a vasopressor agent; or (iv) need for further fluid resuscitation as determined by the treating physician after receiving at least $1 \mathrm{~L}$ of crystalloid fluid within the first eight hours of the first hypotensive event;

2) at least two criteria of the systemic inflammatory response syndrome: (i) heart rate $>90 \cdot \mathrm{min}^{-1}$, or 


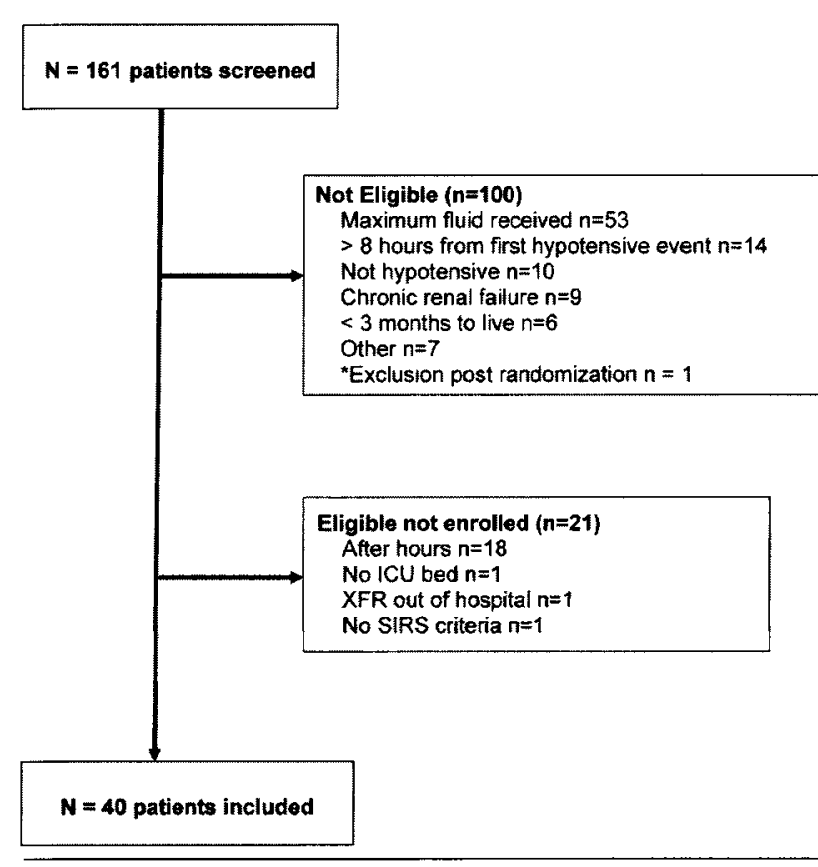

FIGURE 1 Patient flow diagram. XFR = transfer; SIRS = systemic inflammatory responses syndrome criteria. ${ }^{*}$ One patient was excluded post randomization due to meeting an exclusion criterion (chronic renal failure on dialysis).

paced rhythm, or treatment with beta-blockers or the calcium channel blockers verapamil or diltiazem; (ii) respiratory rate $>20 \cdot \mathrm{min}^{-1}$ or an arterial partial $\mathrm{CO}_{2}$ pressure $\left(\mathrm{PaCO}_{2}\right)<32 \mathrm{mmHg}$ or mechanical ventilation; (iii) temperature $>38$ or $<36^{\circ} \mathrm{C}$; (iv) and white blood cell count $>12,000$ or $<4,000 \times 10^{9} \cdot \mathrm{L}^{-1}$, or with more than $10 \%$ bands on the differential; and

3) a suspected or confirmed infectious source. Patients were excluded if they had received more than $500 \mathrm{~mL}$ of colloid ( $5 \%$ albumin or pentastarch) or 2000 $\mathrm{mL}$ of crystalloid fluid, had other forms of shock (hemorrhagic, cardiogenic or obstructive shock), had an acute myocardial infarction or cardiogenic pulmonary edema. Other exclusion criteria were: von Willebrand's disease; a previous severe reaction to hydroxyethyl starches; chronic renal failure requiring dialysis; immediate need for surgery; a contraindication to internal jugular or subclavian line insertion; a projected life expectancy less than three months; age < $18 \mathrm{yr}$; pregnancy or lactation; or a previous admission to ICU with septic shock during the present hospitalization.

\section{Interventions}

Administration of the randomized fluid according to goal-directed algorithm-driven care began immediately after randomization and defined time 0 for both
TABLE I Questions for treating physicians and nurses to ascertain the acceptability of the goal directed algorithms*

\footnotetext{
Questions for treating physicians

Were the goal directed algorithms in this protocol acceptable in the treatment of this patient?

Were the $500 \mathrm{~mL}$ repeat fluid challenges acceptable for this patient?

Was the central venous oxygen saturation goal acceptable for this patient?

Was the evaluation for the optimal CVP range acceptable for this patient?

Was the target hemoglobin of $>80 \mathrm{~g} \cdot \mathrm{L}^{-1}$ acceptable for this patient when $\mathrm{ScvO}_{2}$ was $<70 \%$ ?
}

\section{Questions for treating nurses}

Did the research coordinators adequately support the bedside RN during the initial $12 \mathrm{hr}$ of care for this patient?

Was the workload for this patient acceptable given their critical condition?

Did the physician(s) for this study patient respond within a reasonable time frame for the evaluations required by the algorithms? Were the algorithms in this study easy to understand?

$\mathrm{CVP}=$ central venous pressure $; \mathrm{RN}=$ registered nurse; $\mathrm{ScrO}_{2}=$ central venous oxygen saturation. *Answers to all questions were based on a seven-point Likert scale (range: strongly disagree, disagree, somewhat disagree, neutral, somewhat agree, agree, strongly agree).

study arms (Figure I). The duration of the intervention was the first $12 \mathrm{hr}$ after randomization. Research nurses at each site helped to ensure prompt transfer of these patients to the ICU and aided the treating physicians and nurses in the instruction of the goal directed algorithms. All patients had placement of an arterial line in the radial or femoral artery and a central venous catheter in either the internal jugular or subclavian vein to continuously monitor central venous oxygen saturation $\left(\mathrm{ScvO}_{2}\right)$, and provide access for the administration of fluids, drugs, and vasoactive agents. Blinded randomized study fluid in both arms was administered as $500 \mathrm{~mL}$ boluses in pressure bags according to the algorithm. Patients received a maximum of $28 \mathrm{~mL} \cdot \mathrm{kg}^{-1}$ (or $3000 \mathrm{~mL}$ ) of study fluid during the $12 \mathrm{hr}$ study period. If more fluid was needed, patients received open label $500 \mathrm{~mL}$ boluses of normal saline for the remainder of the $12 \mathrm{hr}$ period. After 12 $\mathrm{hr}$, the quantity and type of fluid administered was at the discretion of the treating physician. Administration of maintenance fluids, antibiotics, corticosteroids, activated protein $\mathrm{C}$, insulin, sedation, analgesia, nutrition, treatment of fever, and need for intubation and mechanical ventilation was left to the discretion of the treating physician.

The resuscitation algorithms were developed through an iterative process with the co-investigative team, 
intensivists from the Ottawa Hospital, and from results of our Canadian septic shock survey. ${ }^{9}$ Physicians administered repeated $500 \mathrm{~mL}$ boluses of study fluid for an initial central venous pressure (CVP) goal of $8 \mathrm{mmHg}$. Thereafter, physicians evaluated the volume responsiveness of the heart by checking the CVP immediately before and after a study fluid challenge. ${ }^{10,11}$ If the CVP increased by at least $3 \mathrm{mmHg}$ over the minimum target of $8 \mathrm{mmHg}$ after a fluid challenge, then the heart was deemed to be maximally filled and the suggestion was made to not continue with fluid resuscitation. The optimal CVP range was defined as the CVP before and after that fluid challenge. For example, if the CVP was $8 \mathrm{mmHg}$ and upon administration of a blinded fluid challenge it increased to $12 \mathrm{mmHg}$, then the heart was considered to be maximally filled. Therefore, the optimal range was $8-12 \mathrm{mmHg}$. It was suggested to maintain a patient in the optimal CVP range for the duration of the study period and it could be re-evaluated at any time during the study period at the discretion of the treating physician. The mean arterial pressure (MAP) goal was set according to the discretion of the treating physician and this goal was achieved with use of fluids and vasopressor agents including norepinephrine, phenylephrine, dopamine, vasopressin, and epinephrine. Once the patient had adequate intravascular volume and blood pressure defined by the CVP and MAP goals, the $\mathrm{ScrO}_{2}$ was checked. If $\mathrm{ScvO}_{2}$ was $<70 \%$, then red blood cells were administered if hemoglobin was $<80 \mathrm{~g} \cdot \mathrm{L}^{-1}$. If $\mathrm{ScvO}_{2}$ was $<70 \%$ after transfusion, then an inodilator (dobutamine or milrinone) was started to further augment oxygen delivery and achieve an $\mathrm{ScvO}_{2}>70 \%$.

\section{Primary outcome}

The primary outcome were feasibility measures for the pilot randomized controlled trial (RCT), defined as the ability to recruit patients, to examine the effectiveness of blinding the study fluids, and to determine if the resuscitation algorithms were acceptable to the treating physicians and nurses. The recruitment goal was to enrol at least one patient per site per month. To evaluate the adequacy of blinding of the study fluids, physicians and nurses were asked to guess the study fluid at a time after the end of the study period. To determine if the resuscitation algorithms were acceptable, the treating physicians and nurses were asked a series of questions summarized in Table I. Answers were recorded on a seven-point Likert scale (range: strongly disagree, disagree, somewhat disagree, neutral, somewhat agree, agree, strongly agree). An item of the resuscitation algorithm was considered to be acceptable if $90 \%$ of the respondents answered "agree" or "strongly agree" to the corresponding question.

\section{Secondary outcomes}

Secondary outcomes included clinical events such as hospital, 28-day, and 90-day mortality, ICU and hospital length of stay, and organ failure. Organ failure was defined with the Sequential Organ Failure Assessment score (SOFA) ${ }^{12}$ and was recorded daily for the first seven days. The SOFA score includes an assessment of six systems: central nervous, cardiovascular, pulmonary, renal, hematological, and gas trointestinal. The range for individual organ failures are from 0 (normal) to 4 (severe failure). An organ was considered to have failed if the SOFA score was $\geq 3$. Safety of the study fluids were examined with coagulation profiles (international normalized ratio, partial thromboplastin time and platelets), measures of pulmonary oxygenation (arterial partial pressure/fraction of oxygenation ( $\mathrm{P} / \mathrm{F}$ ratio $)$ ), and creatinine levels measured daily for the first $72 \mathrm{hr}$ after randomization, as well as the requirement for dialysis at any time during hospitalization.

\section{Randomization, allocation concealment, and blinding procedures}

Patients were randomized using a central computerized permuted four-block randomization scheme. An independent bio-statistician at the coordinating center generated the randomization scheme. Only the designated research pharmacist at each institution was aware of the treatment allocation for individual patients. Study fluids were prepared and blinded ahead of time by the site research pharmacist. Fluids were repackaged using sterile technique into identical $500 \mathrm{~mL}$ polyvinyl chloride intravenous infusion bags with $0.1 \mathrm{~mL}$ of multivitamin (Sandoz Canada Inc., Boucherville, QC, Canada) added to each bag of normal saline to make the fluids identical in colour and texture at the Canadian centres. In preliminary tests, only $27 \%(9 / 33)$ of intensivists correctly identified pentastarch when re-packaged as a study fluid. Fluids at the Middlemore Hospital in New Zealand were blinded with use of opaque bags that covered the study fluid because we were unable to adequately match the colour of normal saline to pentastarch with the intravenous multivitamins.

\section{Statistical methods}

No formal sample size was calculated for this study. Investigators agreed that 48 patients would provide sufficient information to evaluate the three feasibility measures described in primary outcome section. Descriptive variables that were categorical in nature were described using proportions. Continuous variables were described with means and standard deviations, or 
with medians and interquartile ranges for data that were not normally distributed. Categorical outcomes were compared between the groups using Chi-square tests or Fisher's exact tests in the case of small expected cell counts. Differences between the groups were estimated by means of relative risks with $95 \%$ confidence intervals. Continuous (length of stay) non-parametric outcomes were compared between the groups by means of Wilcoxon 2-sample tests. Longitudinal variables (e.g., organ failure measured on days one, three and seven) were compared between the groups using mixed-effects regression analysis to account for correlations in outcomes measured on the same patient over time. Adequacy of blinding of the study fluids was calculated with a Chi-square test. All statistical tests were carried out at the $5 \%$ level of significance.

\section{Results}

\section{Screening and participants}

A total of 161 patients were screened; 121 patients were excluded, leaving 40 patients eligible and enrolled into the trial (Figure 1). Consent was deferred for $73 \%$ $(n=29)$ patients and granted by the substitute decision maker $80 \%(n=32)$ of the time. When consent was deferred, it was obtained from the research coordinators a median of $6.3 \mathrm{hr}$ (interquartile range 3,120 ) after randomization into the trial. The most common reasons for exclusion were because they had received too much fluid prior to randomization $(n=53)$, more than eight hours had passed since the first hypotensive event $(n=14)$, and patients were not hypotensive after receiving the minimum fluid for inclusion $(n=$ $10)$. The most common reason for not enrolling an eligible patient was a patient being eligible during non-working hours for research coordinators $(n=18)$. One patient was excluded post randomization because of meeting an exclusion criterion (chronic renal failure requiring dialysis).

A total of 40 patients were recruited across three Canadian and one New Zealand centres between April 2004 and June 2006. Although the original planned sample size was 48 patients, the decision was made to terminate the study after 40 patients had been enrolled due to lower than anticipated recruitment and because a recently completed but not yet fully published trial comparing a hydroxyethyl starch $p s$ Ringer's lactate in the setting of severe sepsis and septic shock found an increased requirement for dialysis in the pentastarch group. ${ }^{5}$

\section{Baseline characteristics}

Baseline characteristics for patients in the normal saline and pentastarch groups appeared similar with
TABLE II Baseline characteristics

\begin{tabular}{|c|c|c|}
\hline & $\begin{array}{l}\text { Normal saline } \\
(n=19)\end{array}$ & $\begin{array}{l}\text { Pentastarch } \\
(n=21)\end{array}$ \\
\hline Age $(y r)(m e a n \pm S D)$ & $63.6 \pm 16.3$ & $63.1 \pm 13.1$ \\
\hline Female, $n(\%)$ & $8(42)$ & $8(38)$ \\
\hline Apache II score $($ mean $\pm S D)$ & $20.2 \pm 6.3$ & $21.1 \pm 6.1$ \\
\hline \multicolumn{3}{|l|}{ Co-morbidities, $n(\%)$} \\
\hline 0 & $1(5)$ & $4(19)$ \\
\hline $1-2$ & $12(63)$ & $9(43)$ \\
\hline$\geq 3$ & $6(32)$ & $8(38)$ \\
\hline \multicolumn{3}{|l|}{ Type of admission, $n$ (\%) } \\
\hline Medical & $17(90)$ & $21(100)$ \\
\hline Urgent surgical & 0 & 0 \\
\hline Elective surgical & $2(10)$ & 0 \\
\hline \multicolumn{3}{|l|}{ Location at randomization, $n(\%)$} \\
\hline ICU & $6(32)$ & $5(24)$ \\
\hline $\mathrm{ED}$ & $8(42)$ & $14(67)$ \\
\hline Hospital floor & $4(21)$ & $2(9)$ \\
\hline Other & $l(5)$ & 0 \\
\hline \multicolumn{3}{|l|}{ Intensity of support at baseline, $n(\%)$} \\
\hline Vasopressors & $6(32)$ & $12(57)$ \\
\hline *Inodilators & 0 & 0 \\
\hline Ventilation & $13(68)$ & $15(71)$ \\
\hline Dialysis (any type) & 0 & 0 \\
\hline $\begin{array}{l}\text { Time to randomization (br) } \\
\text { (median (IQR)) }\end{array}$ & $1.2(0.9,2.3)$ & $1.5(1.0,3.0)$ \\
\hline \multicolumn{3}{|l|}{ Vital signs (mean $\pm S D)$} \\
\hline $\mathrm{MAP}(\mathrm{mmHg})$ & $60.9 \pm 7.5$ & $59.7 \pm 10.8$ \\
\hline Heart rate $\left(\mathrm{min}^{-1}\right)$ & $101.5 \pm 21.0$ & $101.7 \pm 17.0$ \\
\hline Respiratory rate $\left(\mathrm{min}^{-1}\right)$ & $22.3 \pm 8.7$ & $23.4 \pm 8.4$ \\
\hline Temperature $\left({ }^{\circ} \mathrm{C}\right)$ & $36.8 \pm 1.1$ & $37.5 \pm 1.5$ \\
\hline Glasgow coma score & $13.1 \pm 3.1$ & $13.0 \pm 3.4$ \\
\hline \multicolumn{2}{|l|}{ Individual organ failures $n(\%)$} & $1.2(1.0)$ \\
\hline Pulmonary $(\mathrm{P} / \mathrm{F}<200+$ ventilation $)$ & $5(26)$ & $3(14)$ \\
\hline Renal $($ creatinine $\geq 300 \mu \mathrm{mol} / \mathrm{L}$ ) & $3(16)$ & $1(5)$ \\
\hline Gastrointestinal (Bilinubin $>101 \mu \mathrm{mol} \cdot \mathrm{L}^{-1}$ ) & $1(5)$ & $1(5)$ \\
\hline Hematological (Platelets $<50 \times 10^{9} \cdot \mathrm{L}^{-1}$ ) & $6(32)$ & $4(19)$ \\
\hline Neurological (Glasgow coma score $<10$ ) & $4(21)$ & $4(19)$ \\
\hline
\end{tabular}

ICU = intensive care unit; ED = emergency department;

$\mathrm{IQR}=$ interquartile range; $\mathrm{MAP}=$ mean arterial pressure;

$\mathrm{P} / \mathrm{F}=$ partial pressure oxygen/fraction of inspired oxygen;

*Inodilators = dobutamine or milrinone; ${ }^{*}$ Organ failure defined

by a Sequential Organ Failure Assessment (SOFA) 12 score of $\geq 3$.

exception of the need for organ support at baseline (Table II). Fewer patients in the normal saline group than in the pentastarch group were on a vasopressor at baseline [6 (32\%) vs $12(57 \%)$ respectively]. The number of organ failures was similar between the two groups $(1.3 \pm 1.0$ for normal saline and $1.2 \pm 1.0$ for pentastarch). One of the patients in the normal saline group had chronic renal failure requiring dialysis at baseline and hence was incorrectly randomized into the trial. Six (32\%) patients in the normal saline group as compared to four (19\%) patients in the pentastarch 


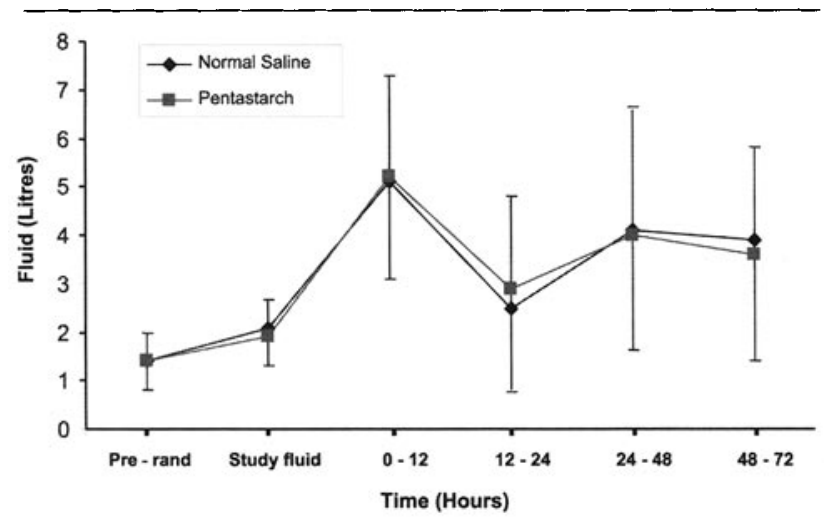

FIGURE 2 Fluid administered against time. Pre - rand $=$ amount of fluid boluses administered pre-randomization; Study fluid = total amount of study fluid administered over $12 \mathrm{hr}$ study period; $0-12=$ total amount of fluid administered over the $12 \mathrm{hr}$ study period (includes the study fluid); $12-24,24-48$, and $48-72$ reflect the total amount of fluid administered in each of the time period.

group had hematological organ failure at baseline. Patients in the normal saline and pentastarch groups were enrolled into this trial within 1.2 [interquartile range (IQR) $0.9,2.3]$ and 1.5 (IQR 1.0, 3.0) hr respectively.

\section{Feasibility outcomes}

The overall recruitment rate was 0.75 patients/site/ month. Only $56 \%$ of physicians and $54 \%$ of nurses identified correctly the study fluid. These proportions are not statistically different from random guessing ( $P=0.46$ for physicians and $P=0.67$ for nurses). The algorithms were found to be acceptable to $97 \%$ of physicians. The hemoglobin target of $80 \mathrm{~g} \cdot \mathrm{L}^{-1}$ and the evaluation of the optimal CVP range was acceptable to $83 \%$ and $73 \%$ of physicians, respectively. The bedside nurses reported that they were well supported by the research nurses $(96 \%)$ during the $12 \mathrm{hr}$ study period. The bedside nurses found the algorithms easy to understand $48 \%$ of the time and $69 \%$ found both the workload to be acceptable and the physician response time to be reasonable.

\section{Fluid resuscitation and clinical outcomes}

Patients in the normal saline and pentastarch groups received a similar quantity of fluid prior to randomization $(1.4 \pm 0.5$ vs $1.4 \pm 0.6 \mathrm{~L})$ and for the $12 \mathrm{hr}$ intervention period $(5.1 \pm 2.1$ vs $5.2 \pm 1.9 \mathrm{~L}$ ) (Figure 2 ). The total amount of study fluid received in the normal saline and pentastarch groups was also similar $(2.1 \pm$ 0.6 vs $1.9 \pm 0.6 \mathrm{~L}$ ). Two patients in the pentastarch study arm received open label pentastarch during the study period. During the study period, the MAP ( $\geq 65$ $\mathrm{mmHg}$ ) and CVP ( $\geq 8 \mathrm{mmHg}$ ) goals were met to a similar extent between the two study groups (data not shown). The $\mathrm{ScvO}$, goal was met less frequently over the $12 \mathrm{hr}$ study period for the pentastarch than for the normal saline group $(P=0.01)$ (data not shown). More patients in the pentastarch than in the normal saline group required inodilator agents [5 (24\%) vs $0, P=0.05]$. Coagulation parameters, prothrombin time, partial thromboplastin time, and platelets, respiratory function quantified with partial pressure oxygen/fraction of inspired oxygen ratios, and creatinine levels were all similar between the two study groups over the first $72 \mathrm{hr}$ (data not shown). Mortality in the ICU and at 28 days, ICU and hospital length of stay, and organ failure were also similar between the two fluid groups (Table III).

\section{Discussion}

This pilot RCT in early septic shock provided essential information that will aid in the development of our next fluid resuscitation trial. Recruitment into this trial was challenging. It was lower than expected and lower than what we will need for a larger trial. We demonstrated that we were able to successfully blind the study fluids for those treating nurses and physicians who answered the blinding question. The resuscitation algorithms were deemed to be acceptable to the treating physicians. However, specific nodes in the algorithms that were less acceptable to the treating physicians included the optimal CVP range and hemoglobin target. The resuscitation algorithms were complicated for the bedside nurses and labour intensive for the research co-ordinators.

Resuscitation research is difficult to conduct due to the tight time line for identification and enrolment of patients, and because of the need to administer randomized interventions immediately. Prior to study start up, we educated the nurses and physicians in the ED and ICU about the trial during formal grand rounds and multiple educational sessions. During the recruitment phase, we ensured that the research nurses provided twice daily reminders to the ED and the ICU teams about the study, and we ensured signage in the $\mathrm{ED}$ to provide further reminders. However, more could have been done to enhance recruitment. For example, we believe it is imperative to identify an ED physician champion at each participating site, as nearly $50 \%$ of patients we recruited were identified in the ED. Early resuscitation teams or ICU outreach teams now exist in many hospitals in Canada and worldwide. These teams could also help to identify eligible patients expeditiously for a future resuscitation trial. 
TABLE III Co-interventions and clinical outcomes

\begin{tabular}{|c|c|c|c|c|}
\hline & $\begin{array}{l}\text { Normal saline } \\
(n=19)\end{array}$ & $\begin{array}{l}\text { Pentastarch } \\
(n=21)\end{array}$ & $\begin{array}{l}\text { Relative risk } \\
(95 \% C I)\end{array}$ & $P$ palue \\
\hline \multicolumn{5}{|l|}{ Co-interventions $n(\%)$} \\
\hline${ }^{\star}$ Vasopressor(s) & $15(79)$ & $17(81)$ & $1.0(0.75-1.4)$ & 1.00 \\
\hline * Inodilators & 0 & $5(24)$ & & 0.05 \\
\hline$\star \geq 1 \mathrm{RBC}$ transfusion & $5(26)$ & $10(48)$ & $1.8(0.75-4.3)$ & 0.16 \\
\hline Corticosteroids & $16(84)$ & $14(67)$ & $0.79(0.55-1.13)$ & 0.28 \\
\hline Activated protein $\mathrm{C}$ & $2(10)$ & $4(23)$ & $2.24(0.47-10.7)$ & 0.39 \\
\hline \multicolumn{5}{|l|}{ Outcomes n (\%) } \\
\hline ICU mortality & $6(32)$ & $6(29)$ & $0.90(0.35-2.33)$ & 0.84 \\
\hline 28 day mortality & $6(33)$ & $9(45)$ & $1.35(0.60-3.05)$ & 0.46 \\
\hline ICU LOS median (IQR) & $5(1-13)$ & $7.5(3-13)$ & & 0.33 \\
\hline Hospital LOS median (IQR) & $20(11.5-33.0)$ & $18.5(10-26.5)$ & & 0.86 \\
\hline Dialysis $n(\%)$ & $1(5)$ & $3(14)$ & $2.7(0.3-23.9)$ & 0.61 \\
\hline Organ failure score $($ mean $\pm S D)$ & & & & 0.34 \\
\hline Day 1 & $1.9 \pm 1.6$ & $1.7 \pm 1.0$ & & \\
\hline Day 3 & $1.4 \pm 0.9$ & $1.1 \pm 1.1$ & & \\
\hline Day 7 & $1.2 \pm 1.0$ & $1.1 \pm 1.2$ & & \\
\hline
\end{tabular}

$\mathrm{CI}=$ confidence interval; $\mathrm{RBC}=$ red blood cell $; \mathrm{ICU}=$ intensive care unit; $\mathrm{LOS}=$ length of stay; $\mathrm{IQR}=$ interquartile range; Inodilators = dobutamine or milrinone; vasopressors $=$ norepinephrine, phenylephrine, dopamine, epinephrine, vasopressin. *First 12 hr of study period.

In this trial, we used tightly protocolized goal directed algorithms for the resuscitation of all study patients to provide similar resuscitation between the groups. The bedside nurses found the algorithms to be complicated and the research coordinators found the first several hours of the study to be labour intensive because their presence was required to ensure that the treating physicians and nurses were following the algorithms. For a future resuscitation trial of similar design, a more pragmatic approach to resuscitation such as the use of resuscitation guidelines that are primarily used by the treating physicians instead of stringent goal directed protocols may be more reasonable, since the former reflects what occurs in practice, thereby making a future trial more feasible.

The principles of our goal directed algorithms were similar to a previously published early goal directed resuscitation trial in severe sepsis and septic shock, ${ }^{13}$ but our CVP goal and hemoglobin target differed. In our trial, the initial minimum CVP goal was $8 \mathrm{mmHg}$. We provided an optimal CVP range to give the treating physicians the opportunity to individualize the CVP goal. However, only $73 \%$ of these physicians found this node of the algorithm to be acceptable. The acceptance rate may have been lower due to a lack of consistent clinical evidence that support the correlation between CVP and volume. ${ }^{14-16}$ However, at this point, a CVP measurement still provides an imperfect, yet non-invasive method to indirectly evaluate intravascular filling at any time during the day or night. The measurement of CVP is also cited as part of the Surviving Sepsis Campaign guidelines for management of severe sepsis and septic shock. ${ }^{17}$
A previously published early goal directed resuscitation trial in severe sepsis and septic shock set a hematocrit target of 0.30 (approximate hemoglobin target of $100 \mathrm{~g} \cdot \mathrm{L}^{-1}$ ). We set a lower hemoglobin target of $80 \mathrm{~g} \cdot \mathrm{L}^{-1}{ }^{13}$ for the following reasons. The early goal directed resuscitation trial by Rivers $e t a l .^{13}$ was not designed and did not answer the question of the optimal hemoglobin target in the setting of early septic shock. The Transfusion Requirements in the Critically IIl (TRICC) trial provides the only randomized controlled trial evidence that a red blood cell transfusion trigger of $70 \mathrm{~g} \cdot \mathrm{L}^{-1}$ is safe. Our Canadian ICU early septic shock resuscitation survey suggested that only $7 \%$ of ICU physicians stated they would transfuse at a hemoglobin target of $100 \mathrm{~g} \cdot \mathrm{L}^{-1} ; 77 \%$ of physicians stated they would transfuse at a target of 80 g. $\mathrm{L}^{-1}$ or less, and in our pilot RCT, $83 \%$ of physicians found the hemoglobin target of at least $80 \mathrm{~g} \cdot \mathrm{L}^{-1}$ to be acceptable.

As our trial was ongoing, ancillary emerging evidence about potential harm with HES led us to reconsider the colloid to test in our future trial. A recently published $2 \times 2$ factorial multi-centre RCT in Germany (the VISEP Study) examined the role of insulin therapy and fluid resuscitation in severe sepsis and septic shock. ${ }^{5}$ In 537 patients who were randomized to $10 \%$ pentastarch or lactate-buffered crystalloid, there was a significant increase in acute renal failure and need for renal replacement therapy in the HES as compared to the crystalloid group (35\% ps $23 \%$, $P=0.002$ and $31 \%$ vs $19 \%$ respectively, $P=0.001$ respectively).${ }^{5}$ Although a new fourth generation HES (Voluven) fluid is now available, there are insufficient 
clinical data in septic shock to inform clinicians about safety. Hence, our investigative team plans to examine $5 \%$ albumin as the colloid fluid for comparison in our next trial because it is the other major colloid available for use in Canada and because recent clinical evidence from a subgroup analysis of patients with severe sepsis from the Saline versus Albumin Fluid Evaluation trial suggested a trend toward a reduction in mortality in favour of albumin (30.7\%) as compared with the normal saline group (35.3\%) (relative risk with 95\% CI 0.87-0.74-1.02). . Two multicentre trials evaluating colloid $p s$ crystalloid fluids in Europe are ongoing and may provide further evidence related to harms or benefits of these fluids in the critically ill (website: clinical trials.gov; clinical trial reference numbers: NCT00318942 and NCT0032774).

Pilot trials focused on feasibility provide key information on whether study protocols are suitable for future studies. Highlighting important feasibility challenges, pilot trials often demonstrate the need to refine the best approach to successfully implement methodologically rigorous protocols. Their dissemination avoids publication bias, and provides useful lessons by communicating the real design and implementation challenges, as well as potential solutions, in conducting multi-center trials.

In this pilot trial, our ability to recruit patients was below expectations, although blinding of study fluids was adequate, and resuscitation algorithms were overall acceptable to most physicians. To overcome the recruitment challenges for a future fluid resuscitation trial in early septic shock, we plan to work with an ED physician champion at each center, improve collaboration between the ED and the ICU study physicians, involve early resuscitation teams to care for these patients, use less stringent protocolization of the resuscitation algorithms, and provide additional physician responsibility to supervise the use of the algorithms. The information gained from this trial may also help investigators in the planning and conduct of future fluid resuscitation trials.

\section{References}

I Marik PE, Varon J. Sepsis: state of the art. Dis Mon 2001; 47: 465-532.

2 Hollenberg SM, Abrens TS, Annane D, et al. Practice parameters for hemodynamic support of sepsis in adult patients: 2004 update. Crit Care Med 2004; 32: 1928-48.

3 Vincent JL, Gerlach $H$. Fluid resuscitation in severe sepsis and septic shock: an evidence-based review. Crit Care Med 2004; 32(11 Suppl): S451-4.
4 Finfer $S$, Bellomo $R$, Boyce $N$, et al. A comparison of albumin and saline for fluid resuscitation in the intensive care unit. N Engl J Med 2004; 350: 2247-56.

5 Brunkhorst $F$, Engel $C$, Bloos $F$, et al. Intensive insulin therapy and pentastarch resuscitation in severe sepsis. N Engl J Med 2008; 358: 125-39.

6 Marik PE, Iglesias J. Would the colloid detractors please sit down! Crit Care Med 2000; 28: 2652-4.

7 Vercueil A, Grocott MP, Mythen MG. Physiology, pharmacology, and rationale for colloid administration for the maintenance of effective hemodynamic stability in critically ill patients. Transfus Med Rev 2005; 19 : 93-109.

8 Ernest D, Belzberg AS, Dodek PM. Distribution of normal saline and 5\% albumin infusions in septic patients. Crit Care Med 1999; 27: 46-50.

9 Mcintyre L, Hebert PC, Ferguson D, et al. A survey of Canadian intensivists' resuscitation practices in early septic shock. Crit Care 2007; 11 : R74.

10 Weil MH, Henning RJ. New concepts in the diagnosis and fluid treatment of circulatory shock. Thirteenth Annual Becton, Dickinson and Company Oscar Schwidetsky Memorial Lecture. Anesth Analg 1979; 58: 124-32.

II Vincent $J L$, Weil $M H$. Fluid challenge revisited. Crit Care Med 2006; 34: 1333-7.

12 Vincent $J L$, de Mendonca A, Cantraine $F$, et al. Use of the SOFA score to assess the incidence of organ dysfunction/failure in intensive care units: results of a multicenter, prospective study. Working group on "sepsis-related problems" of the European Society of Intensive Care Medicine. Crit Care Med 1998; 26: 1793-800.

13 Rivers $E$, Nguyen $B$, Havstad $M A$, et al. Early goaldirected therapy in the treatment of severe sepsis and septic shock. N Engl J Med 2001; 345: 1368-77.

14 Michard F, Teboul JL. Predicting fluid responsiveness in ICU patients: a critical analysis of the evidence. Chest 2002; 121: 2000-8.

15 Bland RD, Clarke TL, Harden LB. Rapid infusion of sodium bicarbonate and albumin into high-risk prema ture infants soon after birth: a controlled, prospective trial. Am J Obstet Gynecol 1976; 124: 263-7.

16 Ernest D, Hartman NG, Deane CP, Belzberg AS, Dodek $P M$. Reproducibility of plasma and extracellular fluid volume measurements in critically ill patients. J Nucl Med 1992; 33: 1468-71.

17 Dellinger RP, Carlet JM, Masur H, et al. Surviving sepsis campaign guidelines for management of severe sepsis and septic shock. Crit Care Med 2004; 32 : 858-73. 